\title{
Late postoperative massive bleeding in septorhinoplasty: A prospective study
}

\author{
Safvet Ors MD, Mehmet Ozkose MD
}

S Ors, M Ozkose. Late postoperative massive bleeding in septorhinoplasty: A prospective study. Plast Surg 2016;24(2):96-98.

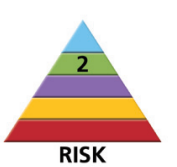

BACKGROUND: There are various complications that can occur in septorhinoplasty, most of which are related to postoperative failure to achieve the desired aesthetic result. However, there are also many other complications, including postoperative bleeding, which is one of the most common nonaesthetic-related complications.

OBJECTIVE: The present study was a prospective analysis involving a total of 750 septorhinoplasty patients, and included individuals who experienced massive bleeding after postoperative day 8 .

RESULTS: The incidence of bleeding was $2 \%$ among all patients. One percent of cases with bleeding occurred between postoperative days 8 and 14 . None of the patients exhibited an abnormality in preoperative or postoperative coagulation tests. Mean blood loss was approximately 1 unit. In all patients, clots in the nose were cleaned, bleeding was subsequently controlled by placement of a polyvinyl alcohol sponge tampon soaked in adrenalin and tranexamic acid, and intravenous administration of $250 \mathrm{mg}$ tranexamic acid in isotonic saline solution. This treatment was sufficient for all cases. None of the patients expereinced recurrent bleeding nor did they require a blood transfusion.

CONCLUSION: Late bleeding in septorhinoplasty is rare. It may be prevented by completely filling the nasal cavity so that there is no dead space between the septal mucosal membranes and the drainage opening. If bleeding occurs, it can be treated by placement of a tampon soaked in adrenalin and tranexamic acid plus intravenous administration of $250 \mathrm{mg}$ tranexamic acid.

Key Words: Bleeding; Complications; Late bleeding; Reasons for bleeding; Septorhinoplasty

$\mathbf{R}$ hinoplasty is an exciting and challenging surgical procedure that $\mathrm{Z}$ is associated with a variety of complications and side effects (1). The complications most frequently reported with rhinoplastic surgery are related to postoperative failure to achieve the desired aesthetic or physiological results. Rhinoplasty is a procedure that is considered to carry high risk, primarily due to the limited predictability of the aesthetic results. Aside from potential postoperative deformities, many other risks and complications must be considered (2). Other complications of rhinoplasty can be categorized as infectious, traumatic, hemorrhagic, systemic and miscellaneous. Serious complications of cosmetic rhinoplasty are extremely rare $(3,4)$.

Aside from aesthetic complaints, postoperative bleeding (eg, epistaxis) is one of the most common complications following nasal surgery. Epistaxis is most frequently mild but may be severe. The most common causes of mild epistaxis are bleeding from the incision sites and traumatized mucosa. Fortunately, mild postoperative bleeding is anterior and generally can be controlled with ease; however, continued bleeding may require the placement of a nasal tampon. Bleeding that persists despite the use of an anterior tampon may indicate posterior bleeding, thus requiring a posterior tampon. Posterior bleeding usually originates from the posterior septal branch of the sphenopalatine artery and distal branch of the anterior ethmoidal artery. Serious bleeding occurs in $<1 \%$ of patients (4).

\section{L'hémorragie massive postopératoire tardive après une septorhinoplastie : une étude prospective}

HISTORIQUE : Plusieurs complications peuvent survenir après une septorhinoplastie. La plupart sont liées à l'incapacité d'obtenir le résultat esthétique souhaité après l'opération. Il existe toutefois de nombreuses autres complications, y compris les hémorragies postopératoires, qui font partie des complications les plus courantes à ne pas être liées à l'esthétisme.

OBJECTIF : La présente analyse prospective portait sur 750 patients ayant subi une septorhinoplastie et incluait des personnes qui avaient subi une hémorragie massive huit jours après l'opération.

RÉSULTATS : L'incidence d'hémorragie s'élevait à $2 \%$ pour l'ensemble des patients. Un pour cent des cas d'hémorragie se sont produits entre le huitième et le quatorzième jour suivant l'opération. Aucun patient ne présentait d'anomalie selon les tests de coagulation préopératoires ou postopératoires. La perte de sang moyenne s'élevait à environ une unité. Chez tous les patients, les caillots dans le nez ont été nettoyés, le saignement a été contrôlé par l'insertion d'un tampon d'alcool polyvinylique en éponge, imbibé d'adrénaline et d'acide tranexamique, et par l'administration intraveineuse de $250 \mathrm{mg}$ d'acide tranexamique dans du sérum physiologique isotonique. Ce traitement a suffi dans tous les cas. Aucun des patients n'a souffert d'hémorragie récurrente ni n'a dû subir de transfusion.

CONCLUSION : L'hémorragie tardive est rare après une septorhinoplastie. Pour l'éviter, on peut remplir complètement la cavité nasale, pour combler tout l'espace entre les muqueuses du cartilage triangulaire et l'ouverture de drainage. Pour traiter un saignement, on peut insérer un tampon imbibé d'adrénaline et d'acide tranexamique et administrer $250 \mathrm{mg}$ d'acide tranexamique par voie intraveineuse.

Following rhinoplasty, bleeding is usually seen within the first week, often in the first two to three days. If there is no underlying pathology, bleeding is not typical after seven days (5-7). Severe bleeding after this period is generally posterior, which always requires use of nasal tampons and additional intervention. In cases of such unusual bleeding, determination of the cause should be sought, for example anticoagulant drug usage, coagulopathy or herbal therapies.

The present study examined patients who experienced massive bleeding after postoperative day 8 and the treatment strategies used.

\section{METHODS}

The present study was a prospective analysis invovling a total of 750 septorhinoplasty patients who were operated on between 2011 and 2014 at one clinic by the same plastic surgeon. Preoperative complete blood count, biochemical (urea, creatinine, aspartate aminotransferase, alanine aminotransferase, electrolytes) and coagulation tests (prothrombin [PT], activated partial thromboplastin time [aPTT] and international normalized ratio [INR]) were routinely performed in all patients. All patients underwent the procedure using the open technique. Follow-up periods ranged from two months to three years, with a mean follow-up duration of two years. 
TABLE 1

Coagulation tests used in routine scanning tests and some features

\begin{tabular}{llll}
\hline Test & Indicator & $\begin{array}{c}\text { Factors } \\
\text { involved }\end{array}$ & $\begin{array}{c}\text { Affecting } \\
\text { disorders }\end{array}$ \\
\hline $\begin{array}{l}\text { Prothrombin time, } \\
\text { international }\end{array}$ & $\begin{array}{c}\text { Extrinsic } \\
\text { coagulation }\end{array}$ & FI, FVII, FX, Oral anticoagulants, \\
normalized ratio & pathways disorder & & $\begin{array}{l}\text { vitamin K deficiency, } \\
\text { liver diseases }\end{array}$ \\
$\begin{array}{l}\text { Activated partial } \\
\text { thromboplastin } \\
\text { time }\end{array}$ & $\begin{array}{c}\text { Intrinsic coagulation } \\
\text { pathways disorder }\end{array}$ & FVII, FII, FV, & Hemophilia A and B, \\
& & FX, FXI, & von Willebrand \\
& & FXII & disease \\
Thrombin time & Conversion of & FI & Afibrinogenemia, \\
& fibrinogen to fibrin & & hypofibrinogenemia, \\
& & & heparin therapy, \\
& & & fibrin degradation \\
& & & products, \\
& & & dysfibrinogenemia \\
\hline
\end{tabular}

\section{RESULTS}

The mean age of the patients was 29 years (range 17 to 58 years), $61 \%$ were female and $39 \%$ were male. While the incidence of bleeding was $2 \%$ in all patients, in $1 \%$ of the cases, bleeding occurred between postoperative days 8 and 14. Six patients with late postoperative bleeding were male and two were female. For seven of these patients, it was their first rhinoplastic operation and, for one, it was their second. None of the patients exhibited abnormality in preoperative or postoperative coagulation tests. For all patients, PT, aPTT, INR and thrombin time (TT) values were within normal limits. All of the patients with hemorrhage had severe deviation in nasal septum and nasal crest; hence, posterior septum excision was performed to open the airway. Postoperative bleeding resulted in an average blood loss of approximately 1 unit. This amount was calculated according to the amount of blood in the aspirator and gauze. In these patients, clots in the nose were cleaned, subsequent bleeding was controlled by placement of a polyvinyl alcohol sponge tampon soaked in adrenalin and tranexamic acid, in addition to intravenous administration of $250 \mathrm{mg}$ tranexamic acid in an isotonic saline solution. Patients were hospitalized for follow-up and were discharged after determination that bleeding had completely stopped. The patients typically stayed one night in the hospital. Tampons were removed after three days. This treatment alone was sufficient in all cases. None of the patients experienced recurrent bleeding after removal of the tampons nor did they require a blood transfusion. None of the patients required revisional surgery at a later date.

\section{DISCUSSION}

There are a variety of possible complications and side effects that can occur in septorhinoplasty (1), of which postoperative bleeding is one of the most common. Bleeding is usually mild and occurs within the first week, often in the first two to three days, but has been reported as late as day 10. If there is no underlying pathology, late-onset bleeding is unusual $(5-7)$. In the literature, the incidence of early bleeding has generally been reported to range from $2 \%$ to $3.6 \%$ in various studies $(8-13)$. No detailed studies investigating late-onset bleeding were found. In the literature, late-onset bleeding has usually been found to result from a coagulation disorder, with an incidence of approximately $1 \%$. The rates were similar in our study.

Use of acetylsalicylic acid, the presence of von Willebrand disease (VWD), hemophilia, factor XIII deficiency, factor XI deficiency and primary fibrinolysis are among the causes of bleeding identified in various studies $(6,8,9,12)$. The cause is unclear for $80 \%$ to $85 \%$ of bleeding. Faber et al (8) reported bleeding in nine of $268(3.4 \%)$ patients, identifying Von Willebrand factor (VWF) deficiency as the cause in two patients while the cause of bleeding in the remaining seven was unclear. They reported desmopressin to be quite effective
TABLE 2

\section{Different scenarios of coagulation test results and possible reasons}

\begin{tabular}{lc}
\hline Normal PT, aPTT and TT & Platelet number and function disorders, von \\
& Willebrand disease, hereditary hemorrhagic \\
& telangiectasia, Ehlers-Danlos syndrome, \\
& Marfan syndrome, XIII deficiency, \\
& $\alpha_{2}$-antiplasmin deficiency, plasminogen \\
& activator inhibitor-1 deficiency \\
\hline Prolonged PT, normal aPTT Vitamin K deficiency, liver diseases, oral anti- \\
coagulants, FVII deficiency, FVII inhibitor \\
\hline Prolonged aPTT, normal PT Lupus anticoagulants, heparin, hemophilia A-B, \\
FVIII or IX inhibitor, von Willebrand disease, \\
congenital FXI or FXII deficiency \\
\hline Prolonged PT, prolonged deficiency, hypofibrinogenemia, \\
aPTT \\
dysfibrinogenemia, liver diseases, vitamin K \\
deficiency, oral anticoagulants, DIC, acquired \\
FX deficiency \\
\hline Hypofibrinogenemia, dysfibrinogenemia, \\
increased fibrin degradation products, \\
thrombin inhibitors, heparin-like \\
anticoagulants
\end{tabular}

aPTT Activated partial thromboplastin time; prothrombin time; DIC Disseminated intravascular coagulation; F Factor; PT Prothrombin time; TT Thrombin time

in reducing bleeding during intra- and postoperative periods (8). Karabulut et al (6) reported recurrent bleeding due to factor XIII deficiency on postoperative day 4. Goldwyn (9) reported bleeding resulting from factor XIII deficiency and acetylsalicylic acid in two patients, and Seligsohn and Man (12) reported severe bleeding and shock due to primary fibrinolysis.

None of our patients exhibited a pathology in preoperative coagulation tests. Postoperative coagulation tests were also within the normal limits. Coagulation tests, which were used as a routine scanning test, along with some other details, are shown in Table 1. However, it should be noted that there are some coagulopathies in which routine coagulation test results are normal such as PT and PTT. Related disorders include factor XIII deficiency, $\alpha_{2}$-antiplasmin deficiency, plasminogen activator inhibitor-1 deficiency, VWD, hereditary hemorrhagic telangiectasia, Ehlers-Danlos syndrome and Marfan syndrome. On recurrent bleeding, the possible presence of these disorders should be considered. Different scenarios of coagulation tests and their causes are shown in Table 2 (16). The above-mentioned conditions were not detected in any of our patients. Similarly, herbal products known to increase the risk for bleeding, such as garlic, gingko, ginseng, blueberries, chili peppers, horse chestnut, flaxseed, green tea, sage tea, saffron root, ginger, blackseed and echinacea, were not used by any of the patients in the present study. Use of herbal therapy should be questioned when postoperative bleeding is present (17).

Fibrinolysis is believed to have been the possible cause of bleeding in our patients. Fibrinolysis begins to dissolve clots in the septum after the first week, which can affect the vessels in this area and lead to bleeding because fibrin degradation products, consisting of organized clot fibrinolysis, may activate clot fibrinolysis in neighbouring areas.

In our patients, all bleeding was observed after the use of silicone splints. Silicon splints provide support; however, the space-filling effect is limited. They are, therefore, unable to push dissected septal mucosal membranes against one another with sufficient pressure, resulting in a dead space where a clot forms; lysis of this clot leads to bleeding.

In the present study, we used polyvinyl alcohol sponge tampons (used only when there was a postoperative bleed) that swell in the nasal cavity, completely filling the dead space. These tampons push mucosal membranes against one another with sufficient pressure, thus eliminating dead space. Without dead space, blood accumulation, clotting, clot lysis and bleeding do not occur. Following removal of the tampons, none of the patients experienced recurrent bleeding. 
Before silicon splints were used, bleeding was not observed in any patients in whom polyvinyl alcohol sponge tampons were used. Rupture in the mucosal membranes often occurs in patients who have undergone septoplasty, allowing drainage and preventing formation of postoperative septal hematoma. Late-onset bleeding was not observed in patients with intact septal mucosal membranes, unilaterally pierced for drainage. All of these findings support our opinions.

In the literature, many different treatment methods have been reported depending on the cause of bleeding including clot cleaning, tampon placement, suturation, ligation of the anterior etmoit artery, use of desmopressin, fresh frozen plasma, cryoprecipitate and factor XIII concentrate $(4,6,8,9,12,13)$. Additionally, blood transfusion was required for some patients. Our approach consisted of cleaning the clots and placing polyvinyl alcohol sponge tampons soaked in adrenalin and tranexamic acid. Patients were also intravenously given an isotonic saline solution containing $250 \mathrm{mg}$ tranexamic acid, which is an antifibrinolytic agent used to treat bleeding due to fibrinolysis, topically or systemically, in various situations $(14,15)$. On administration of these treatments, bleeding ceased in all patients and no

\section{REFERENCES}

1. Sajjadian A, Guyuron B. Primary rhinoplasty. Aesthet Surg J 2010;30:527-39

2. Rettinger G. Risks and complications of rhinoplasty. Laryngorhinootologie 2007;86(Suppl 1):40-54

3. Lawson W, Kessler S, Biller HF. Unusual and fatal complications of rhinoplasty. Arch Otolaryngol 1983;109:164-9.

4. Cochran CS, Landecker A. Prevention and management of rhinoplasty complications. Plast Reconstr Surg 2008;122:60e-7e.

5. Fordham SD. Controlling intraoperative and postoperative nasal bleeding. Plast Reconstr Surg 1992;90:915-7.

6. Karabulut AB, Aydin H, Mezdegi A, Ademoglu E. Recurrent bleeding following rhinoplasty due to factor XIII deficiency. Plast Reconstr Surg 2001;108:806-7.

7. Foda HM. External rhinoplasty: A critical analysis of 500 cases. J Laryngol Otol 2003;117:473-7.

8. Faber C, Larson K, Amirlak B, Guyuron B. Use of desmopressin for unremitting epistaxis following septorhinoplasty and turbinectomy. Plast Reconstr Surg 2011;128:728e-32e.

9. Goldwyn RM. Unexpected bleeding after elective nasal surgery. Ann Plast Surg 1979;2:201-4. recurrence of bleeding was observed. The fact that the bleeding responded to tranexamic acid treatment supports the hypothesis that bleeding occurred due to fibrinolysis. None of our patients required a blood transfusion.

\section{CONCLUSION}

Late-onset bleeding following septorhinoplasty is rare. Although there is sometimes an underlying cause, it is often not readily apparent. Such bleeding may be prevented by completely filling the nasal cavity so that there is no dead space between the septal mucosal membranes and the drainage opening. If bleeding does occur, placement of a polyvinyl alcohol sponge tampon soaked in adrenalin and tranexamic acid, in additon to intravenous administration of $250 \mathrm{mg}$ tranexamic acid should be considered an effective solution.

DISCLOSURES: The authors have no financial disclosures or conflicts of interest to declare.

10. Klabunde EH, Falces E. Incidence of complications in cosmetic rhinoplasties. Plast Reconstr Surg 1964;34:192-6.

11. Miller T. Immediate postoperative complications of septoplasties and septorhinoplasties. Trans Pac Coast Otoophthalmol Soc Annu Meet 1976;57:201-5

12. Seligsohn U, Man AL. [Massive bleeding due to primary fibrinolysis following rhinoplasty]. Harefuah 1972;1;82:219-20.

13. Tamerin JA. Management of hemorrhage post rhinoplasty. N Y State J Med 1967;15;67:550-1

14. Triplett DA. Coagulation and bleeding disorders: Review and update. Clin Chem 2000;46(8 Pt 2):1260-9.

15. Prentice CR. Basis of antifibrinolytic therapy. J Clin Pathol Suppl (R Coll Pathol) 1980;14:35-40.

16. Nilsson IM. Clinical pharmacology of aminocaproic and tranexamic acids. J Clin Pathol Suppl (R Coll Pathol) 1980;14:41-7.

17. Mohan A, Lahiri A. Herbal medications and plastic surgery: A hidden danger. Aesthetic Plast Surg 2014;38:479-81. 